\title{
Generalized Equations for Potential Water Savings from Rainwater Tanks in Adelaide under Different Climates
}

\author{
Upendra Paudel and Monzur A. Imteaz \\ Department of Civil \& Construction Engineering, Swinburne University of Technology, Melbourne, VIC 3122, Australia.
}

\begin{abstract}
With ever-increasing water demand, authorities around the world are considering different options including water recycling and rainwater harvesting to minimize potable water demand. Among all the alternative options, rainwater harvesting system is the most feasible to minimize potable water demand, This paper presents development of generalised equations for the quantifications of potential water savings under different climatic conditions for an Australian city, Adelaide. An earlier developed daily water balance model, eTank, which can calculate potential water savings in three climatic conditions (dry, average and wet) was used for this purpose. Several relationship graphs of water savings were produced through model calculations for different input parameters, i.e. roof area, tank volume and rainwater demand for each climatic condition. From the produced graphs, three (one for each climatic condition) generalised equations were developed, where water savings were presented as a function of roof area, demand and tank volume. Results from the developed equations were compared with model calculated results under different conditions and it is found that results from the generalised equations are very close to the model calculated results. Such equations are expected to be very helpful for general end users and will encourage them for implementing rainwater harvesting with prior knowledge.
\end{abstract}

\section{Introduction}

Water shortage is a major problem in many parts of the world. Regions which depend on groundwater, due to over-extraction ground water table dropping down significantly. Moreover, due to the impacts of climate change some parts of the world are experiencing less amount of rainfall than average rainfall. As such it is imperative for the scientist, water supply engineers, policy makers and government authorities to think on the reliability and sustainability of the town water supply which is mostly rely on ground/surface water. To reduce the over extraction of ground water and cope with climate change, different stakeholders are emphasizing to use stormwater harvesting systems as one of the alternative options. Among all the stormwater harvesting systems, rainwater harvesting system is getting much more attention because it is easy to harvest and needs lesser or minimal treatment for laundry, toilet flushing and outdoor uses.

There have been several studies around the globe quantifying potential rainwater collection and potable water savings. Vaes and Berlamont [1] developed a model to determine the effectiveness of rainwater tanks and stormwater runoff using long term historical rainfall data. Coombes and Kuczera [2] found that for an individual building with a $150 \mathrm{~m} 2$ roof area and $1-5 \mathrm{~kL}$ tank in Sydney can yield 10-58\% mains water savings (depending on the number of people using the building).
According to Coombes and Kuczera [2], depending on roof area and number of occupants, rainwater tank use can result in mains water annual savings of $18-55 \mathrm{~kL}$ for $1 \mathrm{~kL}$ sized tanks and $25-144 \mathrm{~kL}$ for $10 \mathrm{~kL}$ sized tanks. In Sweden, Villarreal and Dixon [3] investigated water savings potential of stormwater harvesting systems from roof areas. Villarreal and Dixon [3] noted that a mains water saving of $30 \%$ can be achieved using a $40 \mathrm{~m} 3$ sized tank (toilet and washing machine use only). Ghisi et al. [4-5] investigated the water savings potential from rainwater harvesting systems in Brazil and found that average potential for potable water savings to be $12-79 \%$ per year for the cities analysed.

Khastagir and Jayasuriya [6] using historical daily rainfall data analysed reliability of rainwater tanks and presented contours of optimum tank sizes for surrounding areas of Melbourne for a supply reliability of $90 \%$. Muthukumarran et al. [7] found that use of rainwater inside a home in regional Victoria (Australia) can save up to $40 \%$ of potable water use. Farreny et al. [8] examined the quantity and quality of rainwater harvesting in Spain and found that sloping smooth roofs may harvest up to about $50 \%$ more rainwater than flat rough roofs. Mun and Han [9] developed a design and evaluation method for a rainwater harvesting system on the basis of water balance equation and found that a design based on sensitivity analysis and proper management of a rainwater harvesting system should be emphasized to improve the operation efficiency. Some researchers (Aladenola and 
Adeboye) [10] used monthly rainfall data for the analysis of rainwater savings potentials and rainwater tank design. However, Imteaz et al. [11] through a case study in southwest Nigeria using a daily water balance model, has shown that analysis using monthly rainfall data greatly overestimates the required tank size.

Berwanger and Ghisi [12] conducted feasibility analysis for a city in Brazil and commented that rainwater tank will be feasible for only selective cases depending on water demand and roof area. Jung et al. [13] conducted economic feasibility of rainwater tanks for seven major cities of South Korea considering continuous supply of rainwater demand and concluded that to be able to achieve continuous supply the required rainwater tank size is not economically feasible. Due to this fact often a smaller tank is used which requires augmented supply from townwater supply or other sources.

Most of the studies used continuous simulations of historical daily data for a long period (depending on data availability) and eventually making an average of cumulative historical savings (or other model variables). Through such analysis of averaged variables/parameters, rainwater tank users may not get an adequate insight of the expected realistic situation(s) in regards to variability of outcomes as a particular year might have an unusual rainfall pattern compared to usual pattern of occurrences (i.e. sporadic bursts and/or longer dry periods). With the impacts of climate change, such ranges of realistic outcomes are expected to be widening further. To overcome this issue, Imteaz et al. [14] developed a daily water balance model (eTank) for the analysis of rainwater tank outcomes under three different climatic conditions (i.e. dry, average and wet). Through the statistical analysis of historical rainfall data, dry year is defined as annual rainfall value closer to $10^{\text {th }}$ percentile value whereas $50^{\text {th }}$ value is average year and annual rainfall value closer to $90^{\text {th }}$ percentile value is defined as a wet year. Imteaz et al. [15] introduced a factor, Rainwater Accumulation Potential (RAP), which is a ratio of roof area and water demand; and using eTank presented relationships of RAP with rainwater reliability under different climatic conditions for Melbourne city. Incorporating another factor to earlier proposed RAP, this paper presents a modified form of Rainwater Accumulation Potential (RAP), which is the ratio of water demand to roof area multiplied by tank volume and shows relationships of modified RAP with annual savings under different climatic conditions for Adelaide. Eventually, established relationships are presented in the form of generalized equations having only 'roof area' and RAP as independent variables.

\section{Methodology}

The daily water balance model proposed by Imteaz et al. [16] was the basis of eTank development. The model considers daily rainfall, contributing catchment (roof) area, losses (due to leakage, spillage and evaporation), storage (tank) volume and water demand for calculating rainwater tank outcomes; annual rainwater savings, annual overflow, annual townwater use and reliability. In the model, the primary input value is the daily rainfall amount for three differeent years (dry, average and wet years). The daily runoff volume is calculated from daily rainfall amount by multiplying the rainfall amount with the contributing roof area after deducting the losses. For this study, from the produced runoff, a $10 \%$ deduction was applied to account for several losses (first flush, leakage, spilling and evaporation). Generated runoff is diverted to the connected available storage tank. Available storage capacity is compared with the accumulated daily runoff. If the accumulated runoff is bigger than available storage volume, excess water (overflow) is deducted from the accumulated runoff. Amount of water use(s) is deducted from the daily accumulated/stored runoff amount, if sufficient amount of water is available in the storage. In a situation, when sufficient amount of water is not available in the storage, model assumes that the remaining water demand is met from the town water supply. The detailed mathematical procedures, formulations and logical sequences are outlined in Imteaz et al. [17].

The model was used to produce series of curves showing expected annual water savings for different input conditions (roof area, demand, tank size and climate condition). From the generated curves, a set of equations for different roof areas and a particular climate condition were derived using best-fit technique. Best-fit equations for a particular condition was selected with the aim of achieving further relationships among the equations' coefficients and exponents. Eventually, 3 generalised equations were derived each for a particular climate condition. These derived equations are presented in the 'Results' section. As a particular dry/average/wet year may have unusual rainfall patterns (over the year), this study used 5 years' rainfall data for each of the dry, average and wet conditions.

\section{Data}

For the current study, a raingauge station in Adelaide Airport was selected. Daily rainfall data for the station was collected from the Bureau of Meteorology website (http://reg.bom.gov.au/climate/data/). For the station daily rainfall data of 57 years (1956 to 2012) were available. Through statistical analysis of total annual rainfall data, three separate years $(1965,1988$ and 1963) were selected as dry year, average year and wet year. For the selection of 5 years' data, for each of the conditions four additional years were selected in a way that out of these four years, two years are having annual rainfalls immediately higher and the other two years are having annual rainfalls immediately lower than the rainfall amount of above selected years. Selected years and corresponding annual rainfall amounts are shown in Table 1.

\section{Results}

Daily water balance model was simulated with the daily rainfall data for the above-mentioned years to evaluate the annual water savings for different tank sizes $(2500 \mathrm{~L}$, 
$5000 \mathrm{~L}, 7500 \mathrm{~L}$ and $10,000 \mathrm{~L})$ with roof area ranges from $100 \sim 300 \mathrm{~m}^{2}$ and demand from 200 to $500 \mathrm{~L} /$ day. Then graphs of annual water savings with $R A P$ were drawn for different roof areas and climatic conditions (dry, average and wet).

\subsection{Generalized equations}

Figure 1 shows annual water savings as a function of RAP for average year having roof area of $200 \mathrm{~m}^{2}$.

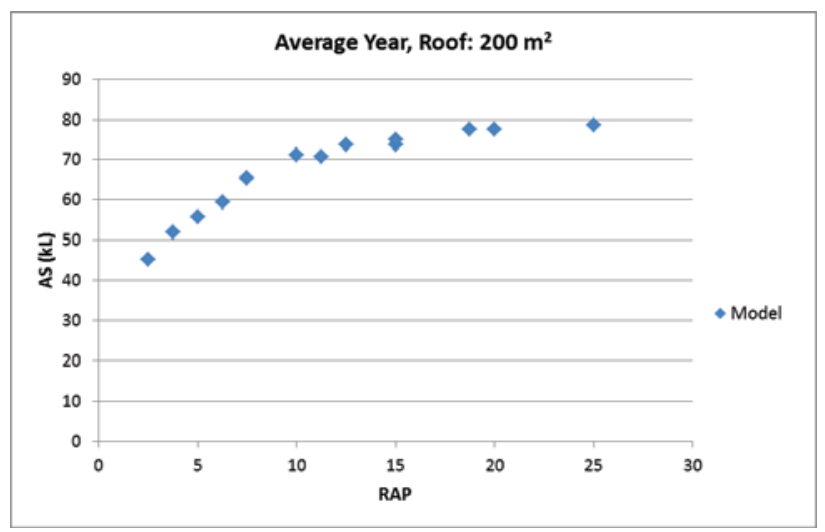

Figure 1. Model calculated annual water savings for different RAP values in an average year having $200 \mathrm{~m}^{2}$ roof areas.

Curve on the Figure 1 can be expressed as a single equation using best-fit technique. Using best-fit technique, five equations each for a particular roof area for the selected average year were derived. The equations are as follow:

Roof Area $100 \mathrm{~m}^{2}: \mathrm{y}=35.245 \mathrm{x}(\mathrm{RAP})^{0.0324}$

Roof area $150 \mathrm{~m}^{2}: \mathrm{y}=38.444 \mathrm{x}(\mathrm{RAP})^{0.1407}$

Roof Area $200 \mathrm{~m}^{2}: \mathrm{y}=37.824 \mathrm{x}(\mathrm{RAP})^{0.2486}$

Roof area $250 \mathrm{~m}^{2}: \mathrm{y}=39.956 \mathrm{x}(\mathrm{RAP})^{0.3}$

Roof area $300 \mathrm{~m}^{2}: \mathrm{y}=42.857 \mathrm{x}(\mathrm{RAP})^{0.3262}$

Where 'RAP' is the Rainwater Accumulation Potential calculated as:

$$
\mathrm{RAP}=(\mathrm{D} \times \mathrm{V}) / \mathrm{RA}
$$

Where, ' $\mathrm{D}$ ' is the rainwater demand in Litre $(\mathrm{L})$, ' $\mathrm{V}$ ' is the tank volume in cubic metre $\left(\mathrm{m}^{3}\right)$ and ' $R A$ ' is the roof area in Square metre $\left(\mathrm{m}^{2}\right)$. Coefficients $(35.245,38.444$, $37.824,39.956$ and 42.857$)$ and exponents $(0.0324$, $0.1407,0.2486,0.3$ and 0.3262 ) of the above set of equations can be correlated with the associated roof areas. Using best-fit technique, above-mentioned coefficients can be expressed as Equation 6 and above-mentioned exponents can be expressed as Equation 7:

$$
\begin{aligned}
& 5.97 \times \ln (\mathrm{RA})+7.66 \\
& 0.28 \times \ln (\mathrm{RA})-1.25
\end{aligned}
$$

Table 1. Selected rainfalls and corresponding years

\begin{tabular}{|c|c|c|}
\hline Climate & Year & Annual Rainfall (mm) \\
\hline \multirow{4}{*}{ Dry } & 2008 & 292 \\
\cline { 2 - 3 } & 2002 & 323 \\
\cline { 2 - 3 } & 1965 & 326.2 \\
\cline { 2 - 3 } & 1994 & 326.6 \\
\cline { 2 - 3 } & 1961 & 328.5 \\
\hline \multirow{4}{*}{ Average } & 1995 & 420.4 \\
\cline { 2 - 3 } & 2004 & 426.3 \\
\cline { 2 - 3 } & 1988 & 441.6 \\
\cline { 2 - 3 } & 2011 & 444.2 \\
\hline \multirow{4}{*}{ Wet } & 1998 & 450.6 \\
\cline { 2 - 3 } & 1960 & 538.7 \\
\cline { 2 - 3 } & 1968 & 570.7 \\
\cline { 2 - 3 } & 1963 & 573.3 \\
\cline { 2 - 3 } & 1983 & 576.2 \\
\hline & 1974 & 586.3 \\
\hline
\end{tabular}

Applying above-mentioned procedure, five equations can be combined into a single equation (Equation 8) having independent variable of 'roof area' and $R A P$. So, annual water savings equation for average year:

$\mathrm{WS}=(5.97 \mathrm{x} \ln (\mathrm{RA})+7.66) \mathrm{x}(\mathrm{RAP})^{0.28 \times \ln (\mathrm{RA})-1.25)}$

Where, WS is the annual water savings in Kilolitres $(\mathrm{kL})$.

Similarly, following the same procedure for the other climatic conditions, two more equations (Equation 9 for dry year and Equation 10 for wet year) for annual water savings were developed:

For dry year:

$\mathrm{WS}=(0.09 \times \ln (\mathrm{RA})-9.23) \times \ln (\mathrm{RAP})+(6.01 \times \ln (\mathrm{RA})$ $+0.84)$

For wet year,

$\mathrm{WS}=(24 \times \ln (\mathrm{RA})-105.25) \times \ln (\mathrm{RAP})+(-7.15 \times \ln (\mathrm{RA})$ $+64.89)$

\subsection{Comparison of results and discussion}

Figure 2 shows the comparisons of model calculated annual water savings values with the developed equation results for dry, average and wet years having roof area of $150 \mathrm{~m}^{2}$. Similarly, figure 3 shows the comparisons of model calculated annual savings results with derived equation produced results having roof area of $250 \mathrm{~m}^{2}$ for dry, average and wet years. The comparisons show the equation developed annual savings results are very close to the results produced by the model (eTank). Only for the roof area of $250 \mathrm{~m}^{2}$ having $R A P$ values of 12.0 and 7.5 for wet year show small deviations from the model produced results. These deviations are not significant as anyway in the wet years there will be enough water to fulfil non-potable water demands. These developed equations are valid for roof areas ranging from 100 to 300 
$\mathrm{m}^{2}$, tank sizes $2500 \mathrm{~L}$ to $10,000 \mathrm{~L}$ and daily water demands $200 \mathrm{~L}$ to $500 \mathrm{~L}$ per day. For other scenario, these equations may not be applicable, although these are the usual scenario practiced/implemented in Australia.
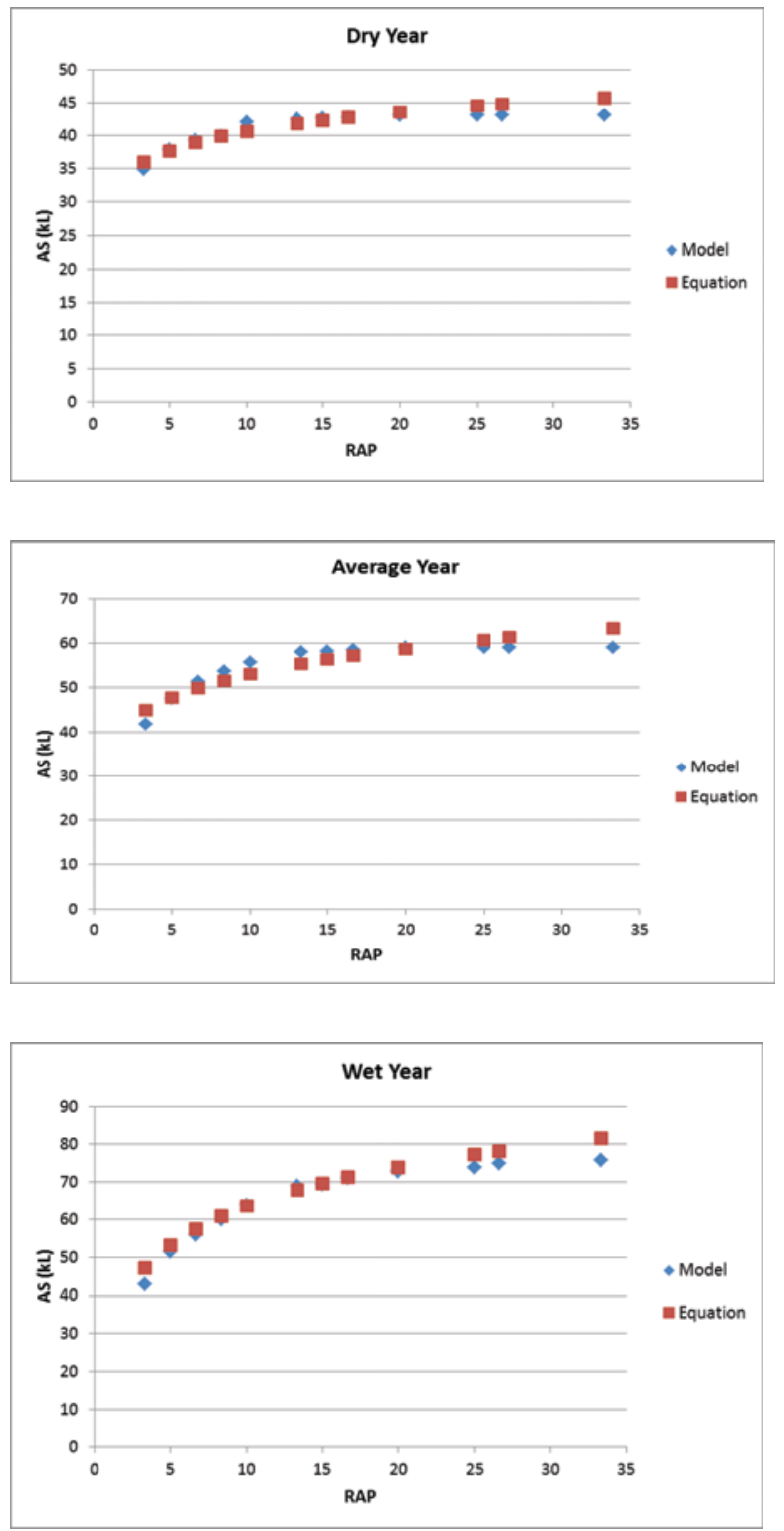

Figure 2. Comparison of model calculated annual water savings with derived equation results in dry, average and wet year for roof areas $150 \mathrm{~m}^{2}$.

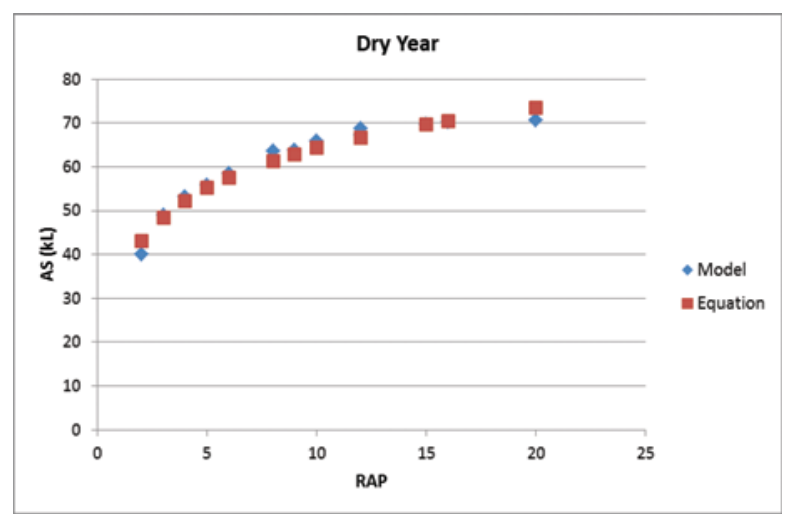

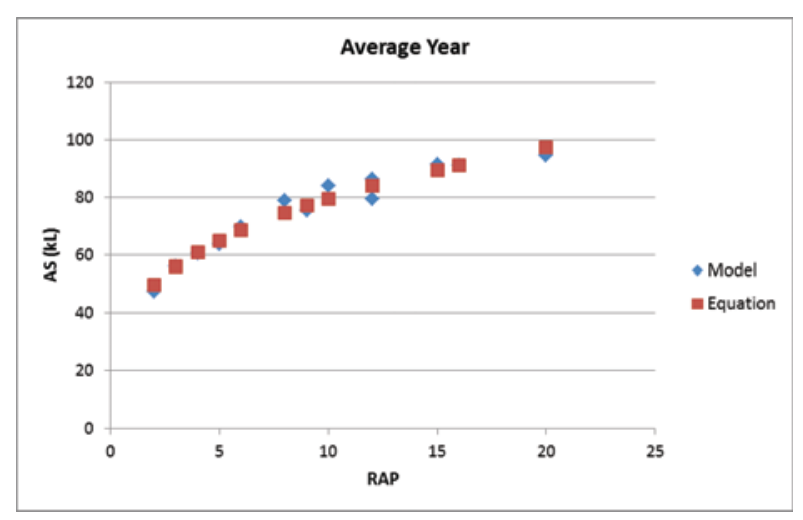

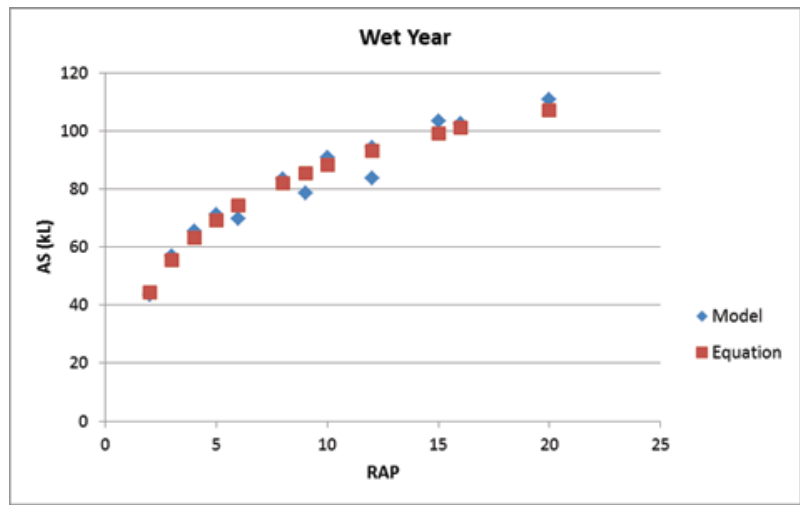

Figure 3. Comparison of model calculated annual water savings with derived equation results in dry, average and wet year for roof areas $250 \mathrm{~m}^{2}$.

\section{Conclusions}

Most of the countries around the world are under severe water stress. Impacts of climate change caused to worsen the situation. Water authorities in those countries struggling to maintain ever-increasing potable water demand and considering different alternatives to minimize potable water demand. For the countries having moderate to high rainfall amounts, among all the alternative options rainwater harvesting is most feasible. However, proper quantification of potential water savings are often misleading. Many studies considered monthly rainfall data for the quantification of water savings; however analysis with monthly rainfall data is unable to produce accurate quantifications, as with the monthly data it is not possible to consider overflow loss, which is likely to happen after consecutive decent rainy days. It is recommended that at least daily (subject to availability) rainfall data must be used for proper quantification of potential water savings. Nonetheless, some researchers used sub-daily (even minute) time-step data. Some other researchers used complex tools/algorithms for such analysis. General end users do not get much benefit through such complex analysis. Moreover, almost all of those complex analysis provide a single answer in regards to potential water savings, which is not realistic. In reality, a range of water savings are expected depending on climatic conditions. eTank is a great tool, which provides expected rainwater savings under three climatic conditions (dry, average and wet). Still many end users 
will struggle to select and upload daily rainfall data from the website provided by the authority. Developed generalised equations are very helpful for such users. General users can easily calculate water savings with the help of a calculator or spreadsheet using these equations. Even these equations can be easily converted to 'mobile app', which will promote uses of rainwater tanks through prior knowledge on potential water savings. It is to be noted that the developed generalized equations are only valid for a particular location (in this instance Adelaide). For other locations, applying the similar procedure different sets of equations can be developed. Generalizing three different climatic equations into single equation can be target for future research.

\section{References}

1. G. Vaes, J. Berlamont, Urban Water J, 3, 303-307 (2001)

2. P. Coombes, G. Kuczera, 28th International Hydrology and Water Resources Symposium, Wollongong, NSW, The Institution of Engineers, Australia, 2, 235-242 (2003)

3. E.L. Villarreal, A. Dixon, Build Environ, 40, 11741184 ( 2005)

4. E. Ghisi, D.L. Bressan, M. Martini, Build Environ, 42,1654-1666 (2007)
5. E. Ghisi, D.F. Tavares, V.L. Rocha, Resour Conserv and Recy, 54, 79-85 (2009)

6. A. Khastagir, N. Jayasuriya, J Hydrol, 381, 181-188 (2010)

7. S. Muthukumaran, K. Baskaran, N. Sexton, Resour Conserv and Recy, 55, 945-952 (2011)

8. R. Farreny, T. Morales-Pinzon, A. Guisasola, C. Taya, J. Rieradevall, X. Gabarrell, Water Res, 45, 3245-3254 (2011)

9. J.S. Mun, M.Y. Han, J Environ Manage, 93, 147-153 (2012)

10. O.O. Aladenola, O.B. Adeboye, Water Resour Manag, 24, 2129-2137 (2010)

11. M.A. Imteaz, O. Adeboye, S. Rayburg, A. Shanableh, Resour Conserv and Recy, 62, 51-55 (2012)

12. H. Berwanger, E. Ghisi, IJSHD, 2(3), 104-114. (2014)

13. K. Jung, T. Lee, B.G. Choi, S. Hong, Water Resour Manag, 29(3), (2014)

14. M.A. Imteaz, R. Karki, A. Shamseldin, and C. Matos, IJCAET (article in press).

15. M.A. Imteaz, A. Ahsan, A. Shanableh, Resour Conserv and Recy, 77, 37-43 (2013)

16. M.A. Imteaz, A. Rauf, A. Aziz, International Congress on Modelling and Simulation MODSIM, Perth. December. 3300-3306 (2011)

17. M.A. Imteaz, A. Shanableh, A. Rahman, A. Ahsan, Resour Conserv and Recy, 55, 1022-1029 (2011) 